\title{
THE IMPLICATIONS OF BREXIT FOR UK COMPETITION LAW AND POLICY
}

\author{
John Fingleton, Amelia Fletcher, Nicholas Forwood, Ali Nikpay, Jon Turner, \\ John Vickers and Richard Whish ${ }^{1}$
}

\begin{abstract}
Brexit raises particular issues for competition law and policy because it is a field in which the European Commission is a major direct actor, and where national authorities - with the UK's playing a notably strong role - operate in a European network. To foster public debate and inform government policy, the authors established the Brexit Competition Law Working Group, and the article that follows is the text of their final report of July 2017. The report has two main themes. First, Brexit should not jeopardise the legislative or institutional continuity of UK competition law. The main pillars of UK competition law - the Competition Act 1998 and the Enterprise Act 2002 - do not require radical reform because of Brexit, though some amendments will be needed. The second theme, however, is the problematic nature of transition to the environment post-Brexit, and of how to secure effective international coordination and cooperation within it. With an end to the 'one-stop shop' for merger assessment, the demands on the UK's Competition and Markets Authority could rise sharply, and unless its resources and capabilities are enhanced, UK competition policy could be weakened just when it needs strengthening.
\end{abstract}

JEL: G34 Mergers, K21 Antitrust Law, L4 Antitrust Issues and Policies

\section{INTRODUCTION}

This Report contains the conclusions and recommendations of the Brexit Competition Law Working Group on the implications of Brexit for UK competition law and policy. It follows the analysis set out in our Issues Paper (October 2016) and our Provisional Conclusions and Recommendations (April $2017)^{2}$ and it draws on the many responses we have had to those papers, both through written contributions and participation in two roundtable workshops (one on antitrust, held in November, and one on mergers, held in December) and a half-day conference at the BIICL in May.

The Report focuses on the impact of Brexit on the various elements of the UK competition regime and the consequent practical implications for enforcement of the competition rules. Our working assumption continues to be that Brexit will result in the UK leaving the European Economic Area ('EEA') and the 'single market'. As well as being the most likely eventual outcome, it has the most farreaching implications for law and policy. There is however a possibility that the UK will remain in the EEA perhaps for a transitional period. That would require much less change than leaving the EU because most EU competition law and practice is replicated in the wider EEA.

We wish to stress aspects of the wider economic policy context at the outset. The first is the broad convergence over the past two decades of competition law and policy and enforcement, not only across the EU, but worldwide - a process in which the UK has played a leading part. Competition law and policy help to ensure that markets work well for consumers and efficient business, and hence for economic productivity, by guarding against anti-competitive practices and mergers. Second, the effectiveness and consistency of policy has been greatly enhanced by international cooperation and coordination, especially between the UK and EU authorities. Third, Brexit will not change the fact that 
all UK firms doing business across Europe will continue to be subject to EU competition law in respect of that business.

The central pillars of competition law in the UK were established 15-20 years ago. They are the Competition Act 1998 ('CA98') and the Enterprise Act 2002 ('EA02'). The Chapter I and Chapter II prohibitions in CA98 prohibit respectively anti-competitive agreements and the abuse of a dominant position: these may be referred to as the 'antitrust' rules. EA02 provides for certain mergers/acquisitions to be investigated and, where a transaction gives rise to a likely substantial lessening of competition ('SLC'), provision is made for its modification or, if necessary, its prohibition. EA02 also provides a mechanism, not present in most peer jurisdictions, whereby markets can be investigated and, where adverse effects on competition are identified, remedies can be imposed to improve the functioning of those markets.

The broad aim of this Report is not to propose radical new policy directions but to help achieve a smooth and effective transition for UK competition policy to a post-Brexit world. As well as maintaining the robustness of policy - to protect consumers and businesses from anti-competitive conduct, agreements and mergers - this involves ensuring that there are no policy gaps, minimising duplication of effort, avoiding unnecessary legal uncertainty and maximising synergies from practical international cooperation.

Our Report has two main themes. The first is that Brexit need not, and should not, jeopardise the legislative or institutional continuity of UK competition law. The two main instruments - CA98 and EA02 - are UK statutes, the Competition and Markets Authority ('CMA') is well-established, and so is the role of the courts (notably the Competition Appeal Tribunal ('CAT')) in this sphere.

The Chapter I and II provisions of CA98 mirror those in Articles 101 and 102 of the Treaty on the Functioning of the European Union ('TFEU'), which facilitates substantive continuity of law. This means that there is no competition law 'gap' to fill upon repeal of the European Communities Act 1972. We do not consider that Articles 101 and 102 should become UK law in relation to agreements and behaviour post-Brexit by virtue of the European Union (Withdrawal) Bill ${ }^{3}$ (the 'Repeal Bill'): they are concerned with restrictions of competition when there are effects on trade between Member States of a Union to which the UK will no longer belong. (If, by its portmanteau nature, the Repeal Bill has the effect of making Articles 101 and 102 UK law for a while, then this may be viewed as sensible in the interim: it would address the fact that, for a period of some years, there will be cases that straddle the pre- and post -Brexit periods. But it would not make sense to retain Articles 101 and 102 UK law in the longer term.)

Some alterations to the substantive antitrust rules will however be required, and we make recommendations on them below. Most salient is the question of section 60 of CA98, which requires consistency between the application of the UK antitrust rules and the jurisprudence of the European Court of Justice ('ECJ'). Such a requirement would be anomalous and undesirable post-Brexit. Should it be amended or simply repealed? On balance, for reasons of continuity, we favour amendment so that the UK authorities and courts should 'have regard to' parallel EU jurisprudence. Amendment to CA98 will also be required in relation to block exemptions from the prohibition on anticompetitive agreements. We also consider that there is a strong case for revising section 2(3) of the Act so that agreements with anti-competitive effects in the UK do not escape prohibition by virtue of being 'implemented' outside the UK.

As for mergers, Brexit need have no direct effect on substantive UK law. The existing UK merger provisions are substantively the same as those in the EU, and are fit for purpose for assessing mergers that would be have been considered by the European Commission ('EC') absent Brexit. We recommend that the SLC test should be retained as the substantive standard to be applied by the CMA; we also recommend that no change be made to the approach to public interest considerations set out in EA02. Further, we see no reason to recommend any change to the substantive test for market investigation references contained in EA02. 
We accept that there is room for debate about more radical changes to the constitution and procedures of UK competition enforcement (such as a prosecution model for antitrust infringements, a compulsory notification regime for mergers, etc.) but we think it would be unwise to link resolution of these questions to Brexit. On the contrary, there will already be sufficient systemic change to which the private and public sector will need to adapt. More radical proposals, some of which were anyway mooted and rejected at the time of the 2013 reforms leading to the Enterprise and Regulatory Reform Act of that year and the establishment of the CMA, would be better revisited, if at all, once Brexit reform has had a chance to bed down. This is consistent with the broad approach of the Government as set out in its White Paper in March that 'wherever practical and sensible, the same laws and rules will apply immediately before and after our departure' and that secondary legislation will not be 'a vehicle for policy changes'. ${ }^{4}$

Our second theme is the problematic nature of transition to the environment post-Brexit, and of how to secure effective international coordination and cooperation within it. Competition policy differs from most other areas of EU legislation in having both EU and domestic enforcement agencies, working closely alongside each other as a network. Associated with this is a system of rules and arrangements which facilitate effective and efficient working across the network. These arrangements give rise to numerous issues of a transitional nature that require careful consideration as a result of Brexit, both in relation to the antitrust rules and merger control (though not market investigations) and it is highly desirable that arrangements be put in place to facilitate coordination and cooperation between the competition authorities in the UK and the EU, both for antitrust and for mergers.

We also recommend that the Government should ensure that the CMA will have adequate resources to enable it to manage the increased workload that will be an inevitable consequence of Brexit. Otherwise there are dangers that the CMA's important other work, including market studies, market investigations, consumer law enforcement and competition advocacy, could be swamped by coping with merger cases that have hitherto been addressed by the EU.

As things stand, the UK will leave the EU at the end of March 2019. Clarifying the practical procedures for transition, coordination and cooperation - both for merger appraisal and antitrust enforcement - is therefore a matter of urgency. Businesses need clarity at least a year in advance. We see no good reason why resolution of such matters needs to be part of the wider Brexit negotiations between the UK and the EU. Political principles are not at stake, and there is a clear common interest in arriving at practical solutions. We recommend that political decision-makers allow, indeed encourage, the respective competition authorities to agree any practical measures that would help to ensure that shared competition policy aims are not frustrated by unnecessary delays.

We set out our recommendations in relation to each of these matters below. Sections II to IV consider substantive issues in antitrust, mergers and market investigations respectively. Then we discuss transitional arrangements (Sections $\mathrm{V}$ and $\mathrm{VI}$ ) and cooperation and coordination in the longer term (Section VII). The question of how to equip the CMA for the prospective increase in its caseload is addressed in Section VIII, and Section IX considers the implications of the possibility that the UK remains, for a transitional period, a member of the European Free Trade Association ('EFTA'), and therefore of the EEA, following exit from the EU. The final Section summarises our conclusions.

\section{SUBSTANTIVE LAW: ANTITRUST}

\section{A. Primary legislation}

The Government's intention is that the Repeal Act will repeal the European Communities Act 1972, which gives direct effect to EU law within the UK. This would mean that Articles 101 and 102 TFEU, which contain the EU antitrust rules, would cease to have direct effect in the UK after Brexit has taken

Legislating for the United Kingdom's withdrawal from the European Union (CM 9446), March 2017, Foreword by David Davis MP. The White Paper further states: 'we will ensure that the power [to use secondary legislation to change the law] will not be available where Government wishes to make a policy change which is not designed to deal with deficiencies in preserved EU-derived law arising out of our exit from the EU' (para 3.17). 
place (although they will remain directly effective until that date). However, we note that clause 4 of the Repeal Bill as published on 13 July 2017 provides that any rights derived from Treaty Articles including Articles 101 and 102 - immediately before Brexit will continue to be recognised and available in domestic law thereafter; clause 7 of the Bill enables a Minister of the Crown by regulation to override the effect of clause 4. While there is good sense in specifying that Articles 101 and 102 should be available in relation to infringements taking place pre-Brexit, or which straddle the preBrexit and post-Brexit periods, we can see no advantages in retaining Articles 101 and 102 in UK law for purely post-Brexit infringements. Those latter cases will only involve harm to competition within the EU internal market, to which the UK will no longer belong, and will concern effects on trade between the remaining Member States.

In any event, the UK antitrust rules, found in Chapter I and Chapter II of CA98, are substantively identical to the EU antitrust rules. ${ }^{5}$ As a result, anti-competitive agreements and the abuse of a dominant position that affect markets in the UK will remain unlawful as a matter of UK law.

Our recommendation is that, subject to clarifying the territorial scope of the Chapter 1 prohibition, the Chapter I and Chapter II prohibitions should remain as they are currently drafted. There is no need to change these provisions as a result of Brexit, and maintaining them in their current form would promote legal certainty for businesses, regulatory authorities and consumers. The UK rules have been in effect since 1 March 2000; there is considerable decisional practice at the level of the CMA and the sectoral regulators; and there is a solid body of jurisprudence in the UK courts explaining their application.

As currently drafted, section 2(3) CA98 applies to agreements 'implemented' in the UK. This formulation of the territorial scope of the Chapter I prohibition derives from the ruling of the ECJ in the so-called Wood Pulp judgment. ${ }^{6}$ According to this jurisdictional test, an agreement entered into and implemented outside the UK, but which produces effects within it, would not be caught by CA98. An example would be a collective boycott of a UK customer by a number of French undertakings: it is not clear that such an agreement could be said to be 'implemented' in the UK, but it could certainly produce effects there. We recommend that section 2(3) be amended to read that the Chapter I prohibition applies to an agreement that is implemented, or that produces direct, substantial and foreseeable effects, in the UK. This change would also reflect more recent ECJ case law which upheld EC competition law fines for agreements implemented outside the EU if they give rise to such effects on EU markets. ${ }^{7}$ There is no need to amend the Chapter II prohibition as section 18 CA98 applies to conduct 'if it may affect trade within the UK'. Ideally we consider that this change should be effected by the Repeal Act itself; otherwise by a statutory instrument ('SI') made under that Act.

Our recommendation is also to leave the criminal cartel offence, contained in section 188 EA02, in its current form, as it provides an important limb of enforcement. Post-Brexit, any constraint on prosecuting that offence in order to avoid impacting the EC in its civil enforcement of the competition rules would fall away. The criminal cartel offence may therefore become a more prominent enforcement tool for the CMA.

Where anticompetitive conduct affects competition within the EU, it will continue to be unlawful as a matter of EU law. Thus, while Articles 101 and 102 will no longer have direct effect in the UK after Brexit, they may be enforced both by the EC and by the competitors and customers of UK businesses in national courts of the Member States. As a result, UK companies that undertake activities capable of affecting inter-state trade in the EU will still need to comply with those provisions.

This has implications for section 60 CA98, which requires, in essence, that Chapter I and Chapter II of CA98 must be interpreted consistently with the jurisprudence of the ECJ. Given the Government's intention to bring an end to the jurisdiction of the ECJ in the UK, it follows that section 60 cannot continue in its current form.

The differences relate to geographical scope and jurisdictional threshold.

Cases 89/95 etc. EU:C:1988:447.

See most recently Case C-227/14P LG Display Co Ltd v Commission EU:C:2015:258. 
Our recommendation is that section 60 should be amended to read that UK courts and regulatory bodies will be required only to 'have regard to' relevant EU Court judgments and EC decisions. ${ }^{8}$ Such an amended provision would free UK competition authorities and courts to depart from the principles of EU jurisprudence and allow the law to evolve over the medium to long term. However, it would also reduce the likelihood of sharp divergences in the short term between the two sets of provisions, by encouraging the courts and regulators to continue to rely on established, well-understood principles. This will promote legal certainty and minimise the burden for UK businesses, including the many businesses that will continue to be required to comply with both the EU and UK rules. ${ }^{9}$

We have devoted much time to debating the future of section 60 . We received some submissions arguing that section 60 should be dropped in its entirety. However, we have concluded that, in the interest of legal certainty, some variant of section 60 should be retained. First, we note in passing that the purpose of section 60 is to influence interpretation of the Chapter I and II prohibitions of CA98: the issue here is not the interpretation of Articles 101 and 102. Secondly, we consider that the duty to 'have regard to' EU precedent should not be onerous. We do not intend that the CMA and the courts should have to devote a large amount of time and resource to explaining why, in an instant case, they have chosen to depart from EU precedent: perhaps this could be explained in a statement to Parliament by the Secretary of State or in the explanatory notes that accompany the Repeal Act (or statutory instrument). Thirdly, we have considered other possible formulations - for example a requirement to 'take into account' EU precedent - but we conclude that 'have regard to' is as good as any alternative expression. Fourthly we consider that this requirement should extend to EU precedent after as well as before Brexit, to prevent UK competition law from becoming ossified unduly as EU competition precedent develops. Finally we recommend that the necessary amendment to section 60CA98 should be effected by the Repeal Act itself; a second-best solution would be for this to be done by SI under the Act.

Consequential amendments will be required to section $25 \mathrm{ff}$ setting out the powers of the CMA to enforce competition law, as these refer to the enforcement of Articles 101 and 102 which will not be appropriate in the case of post-Brexit conduct. However, such amendments will need to allow for the CMA's continued enforcement of Articles 101/102 with regard to pre-Brexit behaviour (see Section V).

\section{B. Exemptions}

The objectives of promoting legal certainty and minimising compliance burdens are also promoted by the various EU Block Exemption regulations enacted by the EC that provide a 'safe harbour' for agreements falling within their scope. Under section 10 CA98, these currently also operate to exempt agreements from the domestic Chapter I prohibition - under what is known as a 'parallel exemption' unless and until it is varied or removed by the UK authorities. Block Exemptions are an important element of the antitrust enforcement regime, as they significantly reduce compliance costs and only exempt categories of agreement that overall have a benign effect on competition. We would therefore recommend that, post-Brexit, the UK retain a system of block exemptions. The question is how this should be achieved.

The first option, which we favour, would entail dealing with existing and future Block Exemptions separately. Section 10 CA98 would be repealed, such that future EU Block Exemptions would have no effect as a matter of domestic law. Instead, the UK authorities could enact their own block exemptions under section 6 CA98. In relation to existing Block Exemptions, however, the Repeal Act (or statutory provision made under it) would provide that they would continue to apply to the Chapter I prohibition $^{10}$ until such time as they have expired or the UK authorities amended or revoked their domestic application.

This approach would remove the possibility of future EU Block Exemptions applying domestically by default. However, it would maintain the currently applicable system, increasing legal certainty for

\footnotetext{
$8 \quad$ Relevant authorities would include, as currently, EC decisions as well as EU court judgments.

$9 \quad$ As well as Articles 101 and 102 TFEU discussed above, UK businesses will also need to comply with the antitrust rules in the other 27 Member States, which broadly conform with Articles 101 and 102, and in a number of other jurisdictions around the world where the antitrust regime is modelled on that of the EU. We see benefits for UK consumers, business and public policy in competition laws that are broadly convergent throughout the world. In the same way that they do under section 10 CA98 currently.
} 
business and avoiding a 'gap' that would require immediate legislative action to address. In the longer run, this option also allows the UK greater flexibility, for while future domestic block exemptions could potentially be modelled on future EU Block Exemptions, they could equally be quite different. The principal drawback of this option is that it entails greater work for the authorities in the long run, as they would have to adopt their own Block Exemptions in place of the EU Block Exemptions. In practice, it may also result in a greater divergence between EU and UK law over time.

An alternative option would be to maintain section 10 CA98 in something like its current form. Current and future EU Block Exemptions would continue to exempt agreements from the Chapter I prohibition unless the UK authorities varied or removed the exemption. Maintaining a modified version of section 10 CA98 would probably be less costly for the UK authorities, as less work would be required than if they had to develop and consult on their own domestic Block Exemptions. However, the disadvantages of this approach are, in our view, significant. In particular, once it has left the EU, the UK will not be able to influence the nature and shape of future EU Block Exemptions. If the UK authorities wished to take a different approach, they would have to provide for specific Block Exemptions not to apply and would need to draw up their own domestic Block Exemption in any event, thus reducing any resource savings.

Finally, in relation to exemptions, Schedule 3 to CA98 exempts various categories of agreement from the domestic antitrust rules. The question is whether any of these exemptions should be removed post-Brexit. The UK's withdrawal from the EU should have no impact on the exemptions under paragraphs 1 (planning obligations), 4 (services of general economic interest), 5 (compliance with legal requirements), 6 (avoidance of conflict with international obligations), or 7 (public policy). Paragraph 2 is no longer in operation. That leaves paragraph 3 (EEA regulated markets), paragraph 8 (coal and steel), and paragraph 9 (agricultural products).

Our recommendation is that the exemption in paragraph 9 relating to agricultural products should be removed, as it applies only to the extent necessary to attain the objectives of the Common Agricultural Policy, which presumably will no longer apply to the UK following Brexit. Paragraph 3 exempts agreements and practices related to certain financial markets currently regulated under EU law. The extent to which this exemption would need to be revised will need to be assessed in light of the scope of any agreement reached between the UK and the EU on regulation of these markets post-Brexit. The exemption under paragraph 8 for coal and steel is no longer relevant following the expiry in 2002 of the Treaty establishing the European Coal and Steel Community.

\section{Private actions}

Successive UK governments have sought to make it easier for private parties to bring actions in UK courts based on competition law infringements. Such actions make it easier for UK consumers and businesses to seek redress for wrongs, and also increase the incentives on companies to comply with the law. We see no reason why Brexit should change this policy. ${ }^{11}$

The UK is currently a forum favoured by victims of competition law wrongs for private competition litigation in the EU. This has resulted, in no small part, from effective civil procedure rules in combination with the ready ability to bring a 'follow-on' action (which allows a claimant to rely on the infringement decision of a competition authority as proof of the infringement, effectively limiting the main contentious issues to causation and quantum of damages). Currently, EU infringement decisions, as well as UK infringement decisions, can be the basis for a follow-on action, thus assisting claimants who have suffered from an infringement of Article 101 or Article 102 TFEU $^{12}$ and who satisfy the relevant jurisdictional criteria for bringing a claim in the UK courts. The main question is whether, post-Brexit, it will remain possible for claimants to bring follow-on claims that rely on a decision by the EC that Article 101 and/or 102 has been infringed. In our view, such actions should continue to be possible.

11 As recognised in HM Treasury, Fixing the foundations: creating a more prosperous nation', July 2015, more competitive markets help foster productivity growth.

Section 47A of CA98 provides that EC infringement decisions may be relied on for the purposes of follow-on damages claims in the Competition Appeal Tribunal, and section 58A of CA98 provides for final infringement decisions (including EC decisions) to be binding before the High Court (or in Scotland the Court of Session or sheriff court), as well as in actions for damages and in collective proceedings before the Competition Appeal Tribunal. 
The most obvious way in which this could be achieved would simply be to retain sections 47A and $58 \mathrm{~A}$ of the CA98 as currently drafted. These provisions state that parties may bring actions for infringements of Article 101 and/or 102, and that in determining such actions the court or tribunal is bound by any EC infringement decisions that have become final. Maintaining these provisions would help to provide certainty to UK businesses and consumers that the UK courts will continue to offer an effective means for redress for any infringement of the EU competition rules that has harmed them.

After Brexit, the EC will undoubtedly take a number of infringement decisions relating wholly or partly to pre-Brexit agreements or conduct. Indeed, given that competition investigations can take several years and cartels are often discovered long after they were initiated, there is likely to be a steady stream of such infringement decisions well into the 2020s. In our view, it is difficult to see why such infringement decisions should not continue to be binding in respect of liability in private actions. Such an approach would reflect the legal position as it would have been understood by the parties at the time of the anti-competitive behavior, ${ }^{13}$ and it seems unlikely that the UK competition authorities could or would launch their own investigation into the same activities. ${ }^{14}$

In other cases, post-Brexit EC infringement decisions will concern agreements or conduct that took place after Brexit. The CMA is likely to have legal competence to investigate such activities where they have an effect on trade within the UK. ${ }^{15}$ However, it cannot be assumed that the CMA will carry out parallel investigations into all infringements investigated by the EC that have a UK component. There may well be situations in which the EC has found a breach of the EU competition rules, potentially causing harm to UK companies and consumers, but the CMA has not carried out a UK investigation. In such cases, we consider that it would be in the interests of UK businesses and consumers for them to be able to rely on the Commission's findings (once final) as binding in respect of the infringement issue. They would then additionally need to prove that the infringement has caused them harm.

There was considerable support for the inclusion of this recommendation in our Provisional Conclusions and Recommendations. One or two respondents, however, questioned whether maintaining the possibility of follow-on actions for EU infringement decisions would be appropriate or necessary in a post-Brexit world. For the following reasons, however, we continue to believe that EU follow-on actions benefit UK litigants and that maintaining scope for such actions is not incompatible with Brexit.

First, EU competition infringement decisions would have a binding effect only in respect of actions for breach of EU competition law. They would not bind UK courts or regulators in relation to domestic competition law enforcement, i.e., when they were applying the Chapter I or Chapter II prohibitions. As a result, we do not consider there could be any strong constitutional objection to this approach on the grounds of sovereignty.

Second, actions for breach of the EU competition rules will continue to be brought in UK courts regardless of whether sections $47 \mathrm{~A}$ and $58 \mathrm{~A}$ are retained. The extent to which Articles 101 and 102 and/or or the rights and liabilities created by them will continue to be part of UK law post Brexit is at present unclear. However, it will continue to be possible for parties to bring actions for breach of statutory duty in relation to infringements of Articles 101 and/or 102 which took place before the date of Brexit. Further, parties will be able to make claims in the UK courts relating to infringements of Articles 101 and/or 102 that post-date Brexit as claims for breach of a foreign tort. In such actions, it is not entirely clear that the relevant EC decision would constitute relevant admissible evidence. but it has been clear that national courts could not give judgments that were inconsistent with EC competition decisions at least since 2000 when the ECJ gave judgment in Case C-3444/98 Masterfoods Ltd v HB Ice Cream [2000] ECR I-11369, [2001] 4 CMLR 449.

14 The effect of Article 11(6) of Regulation 1/2003 is that national competition authorities have no competence to investigate matters which have been investigated by the EC. The extent to which elements of Regulation 1/2003 will be maintained in UK law after Brexit is currently unclear, but it is possible that Article 11(6) will continue to operate in respect of pre-Brexit activities. In any event, even if they had the necessary competence it seems unlikely the CMA would regard it as a priority to investigate activities which have already been investigated by the Commission and subject to an infringement decision.

15 That is because the competence of the CMA to initiate investigations is unlikely to be restricted by Article 11(6) of Regulation 1/2003 in respect of post-Brexit activities. 
Maintaining the current statutory position would promote legal certainty and avoid detailed legal arguments as to the precise evidential weight to be placed on the EC decision. It would also make it easier for potential claimants to attract litigation funding, a practical necessity for many of those seeking redress against well-resourced cartel participants or dominant undertakings.

As and when claims for breaches of Articles 101 and 102 are brought as claims for breach of a foreign tort, the usual position would be that expert evidence would be required in order to prove the content of the foreign law as a matter of fact. This would be inefficient, and unnecessary, given the effectively identical nature of the EU and UK competition rules and the familiarity of the UK courts with them. Unless the point is addressed by the Government through a broader provision (e.g., by providing that after Brexit the content of EU law will generally not need to be proved as a fact in the UK courts), we recommend that express provision be made to remove the requirement for the content of the EU competition rules to be proved as a fact in claims.

As regards the rules governing issues central to competition litigation, such as disclosure of evidence, passing-on of overcharges by purchasers to their own customers, and joint and several liability of cartel participants for damage suffered by victims, the UK has already implemented the provisions of Directive 2014/104/EU (the 'Damages Directive') through the Claims in respect of Loss or Damage arising from Competition Infringements (Competition Act 1998 and Other Enactments (Amendment)) Regulations 2017. ${ }^{16}$ These regulations introduce a new section 47F and Schedule 8A into CA98 to give effect to the Directive's provisions. We recommend that the changes introduced by the regulations remain unaltered post-Brexit. We would expect the decisions of the UK courts applying the regulations to be influential in the courts of the European Union, and also that the UK courts would benefit from having regard to (but not being bound by) decisions of EU courts applying in effect the same legislative rules. This approach would to also help ensure that the UK benefits from our courts remaining an attractive venue for competition litigation post-Brexit.

Finally, the extent to which claimants continue to bring claims in the UK for infringements of EU competition law post-Brexit will depend on the applicable rules concerning jurisdiction and enforcement of judgments. As set out in our Issues Paper, we consider this to be beyond the scope of our paper, as these matters extend beyond competition litigation. Nonetheless, we recommend that the potential impact on competition litigation be taken into account when assessing whether or not the UK ought to seek to remain within the current European jurisdictional and enforcement regime post-Brexit.

\section{SUBSTANTIVE LAW: MERGERS}

The EU Merger Regulation ${ }^{17}$ (the 'EUMR') will cease to apply to the UK on Brexit, at least so long as the UK does not remain in the EEA. ${ }^{18}$ The EUMR should not be adopted into UK law at Brexit, since domestic UK merger law is effective and substantively consistent with the EUMR. Procedurally, the EUMR applies only to mergers with a 'Community dimension', and the UK will have left the Community concerned, so it would be incoherent to domesticate the EUMR by way of the Repeal Bill. There are also significant differences between the EU and UK merger statutes, for example in terms of notification rules, which would make retaining parallel legislation unworkable.

Indeed, we see no reason why Brexit should have any direct effect on substantive UK merger law. The current test - whether a merger could give rise to an SLC - is well understood, has a strong pedigree (it is the standard used in the US and elsewhere) and focuses on the right issues. Whilst the EUMR substantive test - whether a merger would significantly impede effective competition - is worded differently, this 'SIEC' test is in practice the same as the UK's SLC test. Unlike in antitrust

\footnotetext{
16 The Claims in respect of Loss or Damage arising from Competition Infringements (Competition Act 1998 and Other Enactments (Amendment)) Regulations 2017 (SI 2017/385) entered into force on 9 March 2017.

Council Regulation (EC) No 139/2004 of 20 January 2004 on the control of concentrations between undertakings Under the EEA Agreement (Agreement on the European Economic Area (OJ 1999 L1/3, 3.1.1999, as amended), the Commission's exclusive jurisdiction is extended to cover the (currently three) EFTA contracting states.
} 
matters, the CMA is not required to take account of EU jurisprudence in deciding how to assess merger cases that fall within its jurisdiction.

A far more significant consequence of Brexit is that the 'one-stop-shop' system of merger review will no longer operate. The EC will no longer be entitled under the EUMR to take account of the effects of a merger on the UK's domestic markets when it is carrying out merger reviews or designing remedies to guard against any anti-competitive effects that may be expected to result from them. There will no longer be a process for the CMA and the EC to refer mergers to each other for review, and the jurisdiction of the CMA over mergers meeting the EU thresholds will no longer be curtailed. ${ }^{19}$

Perhaps most significantly, at least in practical terms, by dropping out of the EUMR, many transactions that would currently face review at EU level will, post-Brexit, also be subject to UK jurisdiction. This has implications for the transaction planning of merging parties who would previously have had the UK aspects of their transaction assessed at EU level. Post-Brexit, such parties will need to consider whether to notify their transaction in the UK.

Where multi-jurisdictional mergers raise significant UK issues, there will also be a clear need for the CMA to work closely with the EC, as well as other authorities internationally, especially in ensuring alignment of remedy design. In addition, the UK may expect to be notified of a number of global mergers which do not raise significant UK issues but where the parties desire legal certainty.

A further consequence of the removal of the UK from the scope of application of the EUMR is that the UK would no longer be bound by Article 21 of the EUMR. This article limits the circumstances in which non-competition considerations can be taken into account in merger reviews, for those cases which fall within the jurisdiction of the EU. Three criteria - public security, plurality of the media and financial stability - are automatically considered 'legitimate' grounds for this purpose; any other reason for intervention must be notified to the EC for its assessment and approval. To date, the EC has rarely permitted interventions in EUMR cases by Member States that go beyond those set out explicitly in Article 21.

Under UK merger law, sections 42 to 68 of EA02 govern 'public interest cases' and 'other special cases'. The three criteria specified in Article 21 of the EUMR are essentially the same as the public interest considerations in EA02.

For a merger within the exclusive jurisdiction of the EC, a Member State cannot intervene on other non-competition grounds unless the EC assesses that the intervention would be compatible with the principles of Union law. This limitation will not apply post-Brexit for mergers which fall within UK jurisdiction: it will therefore be open to the Government, should it wish to do so, to intervene further in such cases by, for example, adding a new public interest criterion to EA02.

The wider question is whether the Government should broaden the set of non-competition criteria in UK merger law. We recommend against doing so.

The competition focus of merger review has created a system that blocks or amends deals that are harmful to economic growth and consumers while allowing those that create efficiencies. ${ }^{20}$ Interventions on specified non-competition grounds (such as national security) can already be made in a disciplined way that does not run counter to the consumer and economic benefits of a competition-focused regime, which include its independence from politics.

Before EA02 came into force the statutory standard for merger appraisal in the UK was the "public interest' and ministers were accordingly the ultimate decision-makers. In practice, however, competition had for many years been the primary criterion by which mergers were assessed, and

19 There may also be consequences for EU merger control post-Brexit, as UK turnover of businesses will be removed from turnover calculations to establish EC jurisdiction. Without a change in the EUMR thresholds, this may reduce the number of cases notifiable to the EC.

20 The Government's recent Green Paper 'Building our Industrial Strategy' recognises the importance of a competitionfocused regime, giving it primacy in the list of factors contributing to the success of the UK market: 'The UK has benefitted greatly from its open economy: pro-competition rules, flexible labour markets, less intrusive regulation and a favourable taxation regime have all made this country an excellent place to do business'. 
ministers generally accepted the advice of the independent competition authorities. EA02 consolidated this position, largely removed ministers from decision making, and increased judicial oversight by establishing the possibility of appeals, in first instance to the CAT. At the same time EA02 retained the possibility of intervention in merger decisions on certain specific non-competition grounds. ${ }^{21}$

That is not to say that non-competition objectives were considered unimportant by successive governments. The point rather was that it was accepted that these objectives were best pursued directly (e.g., through regional policy) rather than by distorting merger policy away from its prime focus on competition. We share this view: in our opinion, using the merger review process indirectly to address non-competition issues would be inefficient and costly, and would risk the re-politicisation of this part of competition policy. Further, maintaining the established competition focus of merger policy would help secure the continuing attractiveness of the UK as a destination for investment and productivity-enhancing activities, by avoiding the imposition of potentially unpredictable and politicised hurdles to obtaining merger clearance for deals. ${ }^{22}$

If, contrary to our recommendation, and to the principle that the Repeal Act should not introduce major alterations to substantive UK law, new non-competition criteria were to be added to UK merger law, we consider that they should be kept as narrow as possible and applied in a disciplined, transparent and objective manner, and subject to judicial oversight and/or review by an independent agency. In this respect, the processes set out in EA02, section 42 et seq could provide a model.

In principle, non-competition considerations can be used both to block pro-competitive mergers and to permit anti-competitive mergers. The latter would be of particular concern, given the harm to consumers and productivity that can arise from anti-competitive mergers. This is not an issue with the existing media plurality criterion, since anti-competitive mergers never increase plurality. Similarly, it does not appear to be an issue with the existing national security criterion. To date, where national security considerations apply they have resulted in takeovers being allowed (rather than prevented) subject to undertakings to protect various defence issues. However, as none was referred for an indepth competition investigation, there is no indication that they have been used to date to secure the approval of an otherwise anti-competitive merger. The financial stability criterion, however, avoided competition scrutiny of the acquisition of HBOS by Lloyds, which may well have turned out to be detrimental to financial stability itself.

\section{SUBSTANTIVE LAW: MARKET INVESTIGATIONS}

Given that the market investigation regime is UK-specific, we have identified only one implication arising from Brexit. Under Article 3(2) Regulation 1/2003, the CMA is constrained from applying stricter treatment to agreements in market investigations ('MIRs') than under Article 101. This provision is designed to ensure that priority in the treatment of agreements that have an effect on trade between Member States is given to EU competition law over domestic competition law. If this provision were to cease to apply post-Brexit, this could potentially allow the CMA to use the market investigation regime more widely than is the case at the moment.

There may be benefits to allowing the CMA to employ MIRs more widely. There may be markets in which agreements, or cumulations of agreements, are considered to be a 'feature' of the market

\footnotetext{
21 Those two grounds were national security and media plurality. Thus, for example, a takeover that does not have the prospect of substantially lessening competition can be blocked on either of those grounds. In 2008 a third noncompetition criterion was added - financial stability - and used to allow a merger between Lloyds and HBOS, which the OFT believed should be referred to the Competition Commission for Phase II review, to be cleared without indepth scrutiny of its effects on competition.

22 To the extent that political concerns relate to the potential for hostile takeovers by foreign companies of UK firms, we note an alternative approach which could mitigate this risk. The 'poison pill' provisions of the UK Takeover Code are more stringent than those in many other jurisdictions. Relaxing these would enable listed UK companies to protect themselves against hostile takeovers more effectively, without any need for political intervention. We have not analysed this alternative in detail, but note that it would also raise issues that would need to be considered carefully. For example, it could weaken the market for corporate control, which is an important driver of efficiency and productivity.
} 
having an adverse effect on competition. To the extent that such agreements have an effect on interstate trade but do not violate Article 101 the CMA cannot, under present law, take action against them under the MIR system. In the future it could, without the need to establish that the agreements violate CA98.

However, there may also be concerns that the CMA might choose to take the 'easy' route of requiring agreements to be modified or abandoned under the MIR provisions rather than under the more stringent standards of CA98; there is a potential for blurring the lines between different tools available to the CMA, which might be considered more serious given that there is a full right of appeal under CA98 but only a more limited judicial review under EA02. Against this, we note that MIR decisions require only changes to future conduct. Unlike CA98 decisions, they do not give rise to a finding of past illegal conduct for which follow-on claims could be brought by affected parties.

On balance, we conclude that it would not be appropriate to retain a domestic equivalent of Article $3(2)$ of Regulation $1 / 2003$. Such a provision would introduce a complexity into the domestic system of competition law that is unnecessary, particular at a time when legal uncertainty is to be avoided wherever possible. However, we do not think that the CMA should have an unfettered discretion in its choice of legal instrument when investigating agreements that might be harmful to competition. One possibility might be for there to be a duty of primacy, requiring the CMA in the first instance to consider using CA98 rather than EA02. This could be modelled on the existing duty of primacy on sectoral regulators when considering whether to use CA98 or their regulatory powers. Alternatively, it may be appropriate for the CMA to consult on when it would be appropriate for it to take action under its MIR powers, as opposed to under the Chapter I prohibition, and then to adopt appropriate guidance on the subject.

\section{TRANSITIONAL ARRANGEMENTS: ANTITRUST}

\section{A. Investigations}

Under the current legal regime, if the EC has initiated proceedings under Articles 101 or 102, the Member State authorities are 'relieved of their competence' to act under those articles (Article 11(6) of Regulation 1/2003). As a separate matter, if under the current legal regime the Member State authorities want to apply their national competition laws to any agreements or conduct which may affect trade between Member States, they are currently obliged also to apply EU competition law to them (Article 3(1) of Regulation 1/2003). Article 3(2) requires that national competition law may not be applied to prohibit agreements which are acceptable under Article 101. The combination of these rules means that there is currently no real scope for the UK authorities to take competition law enforcement action when the EC has opened its own investigation.

Brexit requires separate consideration with respect to cases already opened by the $E C$ at the time of Brexit, and those that might be launched post-Brexit but which relate to pre-Brexit behaviour.

As regards ongoing EC cases involving pre-Brexit agreements or conduct with effects on the UK (as well as other EU) markets, Brexit will by definition have relieved the UK authorities of their competence under Regulation 1/2003 to investigate the matter in parallel under Article 101 or Article 102. Generally, we believe that the EC should and probably will continue, post Brexit, to address the UK aspects of the pre-Brexit conduct under investigation. The conduct under investigation would have taken place when the UK was still a member of the EU, and the EC should wish to ensure that EU competition law was enforced irrespective of the surrounding circumstances. In cases of panEuropean behaviour, the evidence relating to the UK would often be regarded by the EC as helpful in establishing a single overall infringement throughout Europe. It also seems to us that it would be in the interests of the EC to take forward the UK aspects of such cases from a practical viewpoint, not least since it would benefit from the fines imposed relating to UK markets (though, as discussed below, the UK may seek to secure at least a proportion of these monies through the Brexit negotiations). 
If, however, the EC were for any reason to decide that it no longer intended to investigate a suspected infringement of Article 101 or Article 102 insofar as it affected the UK, the CMA would be free postBrexit to commence (or recommence) its own investigation under the Chapter I or Chapter II prohibition. It has been put to us that in those circumstances the CMA may still be under a duty to apply Article 101 or 102 to the pre-Brexit agreement or conduct as well as national competition laws in other words that Article 3 of Regulation 1/2003 may continue to apply in relation to pre-Brexit agreements and conduct. (This may also be true for investigations commenced by the CMA postBrexit but relating to pre-Brexit behaviour.) If this is correct, removing the CMA's power under CA98 to enforce Articles 101 and 102 through the Repeal Act process could put the CMA in a difficult position legally. To avoid this, we would recommend that the CMA's power to apply Articles 101 and 102 in relation to pre-Brexit agreements and conduct be retained.

As regards new cases that might be opened post-Brexit, but which cover pre-Brexit conduct or agreements, it might prove harder for the EC to justify expending resources and time to protect UK markets and consumers. Unless the UK and the EU agree that EC will not de-prioritise the investigation of suspected pre-Brexit infringements, there is a risk that there will be underenforcement of infringements affecting UK markets unless the CMA steps in (based on the application of the Chapter I or Chapter II prohibitions).

This in turn means that we might expect to see the CMA and EC opening parallel cases for pre-Brexit behaviour. Absent effective information-sharing and coordination with the EU, the CMA may not even be aware of the extent of any overlap between its work and the EC's on such cases, while both the $\mathrm{EC}$ and CMA investigations could suffer from not being able to pool information and coordinate their work. In relation to cases concerning Article 101, while Article 3(2) of Regulation 1/2003 would cease to apply as from Brexit, it would be desirable (and consistent with the principles of legal certainty and non-retrospectivity of legislation) that the CMA follow the principle that any infringement action taken under UK law in respect of restrictive agreements or concerted practices does not lead to an outcome inconsistent with the position if Article 101 were applied also (which, for practical purposes, would equate to the EC's decision in the case). Again, this may be difficult to achieve on parallel cases, absent effective information-sharing.

We therefore recommend that the Government give priority to agreeing transitional arrangements with the EU which provide for effective information-sharing and clear case-allocation procedures in respect of pre-Brexit conduct where both the EU and UK competition authorities have the power to take enforcement action in respect of agreements or conduct affecting the UK.

Where the UK does open an investigation in parallel to an investigation by the EC concerning effects in other territories, the arrangements should empower the EC to disclose any relevant information to the CMA (and for the CMA to be able to use this information), and vice versa. Where the CMA does not open a parallel investigation, the transitional arrangements should provide for the current European Competition Network ('ECN') arrangements to continue to apply, to allow the UK to give input (at least as regards the relevant elements of the case).

We note that both of these suggestions might require amendments to EU legislation and may therefore be difficult fully to achieve in the short term. Nonetheless, we strongly recommend that they be included in any transitional discussions, with a view to obtaining these protections to the extent possible at an early stage. There is a strong mutual interest in achieving them with no impact on issues of sovereignty.

\section{B. Leniency}

Important transitional issues arise also in respect of the leniency arrangements that have been developed to encourage disclosure of illegal cartels. For example, should/could the CMA offer conditional immunity to a company that has been granted conditional immunity under the EU leniency 
provisions, but not in the UK (in circumstances where the UK decides to open a cartel case in relation to behaviour that is already being investigated by the EC in respect of territories other than the UK)? ${ }^{23}$

In order to ensure legal certainty, in our view it should be CMA policy to 'adopt' any pre-Brexit conditional leniency granted by the EC in the event that it opens its own parallel investigation (unless a competing applicant has already been granted conditional immunity at the time of the original application). We do not believe that this would in any way harm the UK leniency policy given the unique circumstances of Brexit. We further recommend that the CMA publish guidance/notice to this effect in the run-up to Brexit.

\section{Commitments}

A further transitional issue relates to the status of existing commitments affecting UK markets under Article 9 of Regulation 1 . They are binding for a period of time and, once adopted, mean that the EC can close its file. Post-Brexit, once the UK is no longer a Member State of the EU, it may be unclear whether commitments obtained pre-Brexit would remain binding, at least in respect of the UK. This may depend on their precise wording. Even where they remain binding, however, it is not clear that the EC would have the inclination or even the vires to enforce them. Whilst the CMA could in theory seek new commitments in each of these cases, this could be heavily resource-intensive. ${ }^{24} \mathrm{We}$ recommend instead that they should be 'nationalised' through the Repeal Act process, insofar as they affect the UK, and the CMA given the power to enforce them, and where appropriate amend or terminate them.

\section{Other issues}

Under EU rules, advice given to a company by external EEA-qualified legal counsel is privileged and protected from disclosure in the context of an EC investigation. This protection from disclosure is a key part of the 'rights of defence' under EU competition law. However, once the UK exits the EU, it seems likely (even if not certain) that privilege will no longer be held to apply to the advice given by those solely qualified in the UK. In order to ensure that rights of defence are not undermined, we recommend that transitional arrangements provide for continued recognition of legal professional privilege in EC cases involving investigations relating to pre-Brexit agreements or conduct, where undertakings receive legal advice from UK qualified lawyers both before and after Brexit.

We would also draw attention to the budgetary aspects of fines imposed by the EC post-Brexit for infringements involving wholly or partly pre-Brexit conduct. Fines for competition infringements currently run at billions of Euros annually (more than 22 billion since 2004). Fining decisions are typically adopted many years after the infringements have taken place. Under current rules, fines are entered into the EU budget as receipts only when the fining decision becomes definitive (i.e., when any appeals have been resolved). As a result, post-Brexit, the remaining 27 Member States are likely to receive some tens of billions of Euros in fines relating to pre-Brexit infringements; and these fines may reflect damage done to the UK economy as a result of the agreements and conduct. In the context of the Article 50 negotiations, the Government will no doubt wish to consider whether and how it wishes to raise the question of the appropriate allocation of such monies.

\section{TRANSITIONAL ARRANGEMENTS: MERGERS}

\section{A. Investigations}

\footnotetext{
23 For cases involving pre-Brexit conduct that do not commence until after Brexit, this issue is less likely to arise, as parties would reasonably be expected to make leniency applications in both the UK and the EU.

At present, there are ten commitment decisions in force that affect/potentially affect the UK. Seven of these are EEAwide commitments that could impact UK markets/companies (including, for example, the Visa MIF commitments and the Paramount studio commitments) and three (Samsung; E-books; and BA/AA/IB) specifically involve UK companies and/or UK markets.
} 
Brexit will have a significant impact on merger review for cases that are undergoing EC review at the time of Brexit. Unless the EU revises the EUMR, or unless there is an implementation period during which the UK is treated as being within the EEA for merger review purposes, the EC will lose its jurisdiction to block mergers or accept remedies in relation to their effect on the UK from the moment of Brexit. This will be true even of mergers that have been notified to the EC pre-Brexit.

The loss of the UK as a Member State could also affect the EC's jurisdiction over mergers that meet the EUMR thresholds pre-Brexit and are undergoing review at the time of Brexit. The requirements of Article 6 EUMR may well lead to a number of cases that initially came within the scope of the EUMR no longer doing so at the end of Phase 1 , and thus requiring consideration at national level instead. ${ }^{25}$

These issues create significant challenges for businesses, advisors and officials in handling mergers with UK nexus that are notified under the EUMR and for which the review 'straddles' the date of Brexit. From the UK's perspective, the essential question is how to ensure that the impact of such transactions on UK markets and consumers is properly investigated and remedied, where appropriate.

The provisions of EA02 would allow the CMA to open a parallel investigation into any mergers that meet the UK thresholds and are under EC review at the moment of Brexit. ${ }^{26}$ However, wholesale duplication of merger reviews over this transitional period would be neither desirable nor realistic. Parallel investigations of mergers by the CMA and the EC would put a burden on businesses in terms of cost, process misalignment, and the risk of differing substantive outcomes and/or remedies. It would also create a sudden increase in the CMA's requirements for staff with mergers skills and experience. This may be difficult to establish within a short time frame, even if the requisite funding is available.

To minimise the impact and burden of potential parallel reviews, and avoid a situation where transactions affecting UK market(s) 'fall between two stools' and are not reviewed, we recommend the following.

First, for mergers that have been notified to the EC by the time of Brexit, the CMA should make fullest use possible of its ability under Article 9 of the EUMR to request full or partial reference back to the UK of any notified merger that is likely to have a significant nexus to or impact on the UK. ${ }^{27}$ This will need to be done for a period extending at least eight months prior to the date of Brexit in order to capture cases that could be notified pre-Brexit and enter EUMR Phase II post-Brexit.

The legal requirements for referral are set out in Article 9 and the EC's referral notice discusses in detail the principles governing when a merger can be referred back to a Member State. These will continue to apply in the run-up to Brexit. The key consideration for the CMA will be whether a merger would need UK review because UK-specific remedies may be needed. To provide greater certainty to businesses as to the considerations that the CMA may take into account and the type/extent of engagement that it may have with parties in order to make the necessary determinations, it would be helpful for the CMA to issue guidance on this as the Brexit process develops. It would also be advisable for the CMA to work with the EC to agree a pre-Brexit referral strategy/approach, so as to ensure that the process runs smoothly. This will, of course, depend on the ability and willingness of the EC to engage on this issue, but it would appear to be one of clear mutual interest.

The merging parties themselves might also make use of equivalent provisions under Article 4(4) and pre-emptively request a reference of the UK aspects of any transaction.

\footnotetext{
$25 \quad$ No equivalent decision is open to the EC at the end of Phase 2, implying that if the EC's investigation has already entered the Phase 2 stage at the time of Brexit, the EC will retain vires and will take a decision determining the compatibility of the merger with the competition rules, albeit that it can no longer include the UK within the scope of its findings.

26 The effect of (a) the suspensory effect of the EUMR and (b) the temporal aspects of the 'relevant merger situation' definition under EA02, means that the CMA will have jurisdiction over mergers that meet EA02 thresholds throughout the EC's review process and for a period of four months thereafter.

27 The CMA estimates that Brexit could lead to an increase in the CMA's caseload of $40-50 \%$ since its creation (e.g., an additional 30-50 Phase 1 cases and six Phase 2 cases per year).
} 
For mergers that have been notified to the EC for which the geographic market(s) is EEA-wide or global, and/or the relevant assets that might be subject to a remedy are outside the UK, the Article 9 requirements may not allow the EC to refer the transaction back to the UK for review (in whole or in part). However, a significant 'enforcement gap' is less likely to arise in relation to these transactions merely because the EC's post-Brexit review does not take into account the impact of the transaction on the UK market. This is because the incentives facing the parties, the CMA and the EC should, in most cases, be aligned on matters of procedure. In particular, the UK regime has the advantage, unique in Europe, of allowing merger review post-closure, subject to interim 'hold-separate' powers. As well as reducing the risk of an enforcement gap, this gives the parties incentives to engage proactively with the CMA in a timely way on mergers that might raise UK competition issues. To provide certainty to business, we recommend that the CMA, ideally in conjunction with the EC, publish guidance on how merging parties should engage with both authorities before the date of Brexit to ensure smooth case transition.

Second, for mergers that have not yet been notified at the point of Brexit, it would be sensible for the parties to mergers with a significant UK component to engage in pre-notification contacts with both the EC and the CMA. Where parties approach both authorities, the EC and CMA should agree that they will use the full extent of the information sharing and coordination abilities under the EUMR (supplemented as necessary by consent from the parties) to discuss the most effective allocation of merger review upon Brexit. This may require consideration of the scope of potential remedies, as discussed below.

To reduce uncertainty for businesses and advisors, the CMA should finalise and communicate its policy on such transitional issues nine months before the date of Brexit at the very latest.

\section{B. Remedies and procedural issues}

Mergers that have been approved by the EC subject to conditions raise similar issues to commitment decisions under Article 9 of Regulation 1/2003 (discussed above). However, most commitments offered to remedy competition concerns involve the divestiture of a business or business unit within a relatively short space of time (usually six months). In practice, therefore, merger remedies are unlikely to require long-running post-Brexit enforcement. Nonetheless, to the extent that UK-specific merger remedies have been accepted by the EC pre-Brexit and are still ongoing at the time of Brexit, we recommend that these be 'nationalised' through the Repeal Act, insofar as they affect the UK, and that the CMA be given the power to enforce them.

As with antitrust cases, transitional provisions would be needed to enable continuity of advice and representation (including in respect of appeals) for those mergers that come within the jurisdiction of the EUMR and are undergoing EC review at the time of Brexit. Consistent with this, legal privilege should continue to apply to documents that would have been privileged pre-Brexit.

In addition, for continuity and consistency of merger assessment and remedy implementation across the UK and EU post-Brexit, it is crucial that there can be effective coordination and cooperation between both jurisdictions. This is discussed further in Section VII below. However, as a transitional issue, if there is a risk that finalised arrangements will not be in place by the time of Brexit, then it is important that transitional arrangements are made to enable effective cooperation and coordination over the intervening period.

\section{TRANSITIONAL ARRANGEMENTS: ANTITRUST}

Currently, such coordination and cooperation as is needed between the CMA and EC, for both antitrust and mergers purposes, can be arranged efficiently through the ECN. The ECN also allows for coordination and cooperation between the CMA and the national competition authorities of Member States. Through the ECN, the EC and the Member State competition authorities inform each other of proposed decisions and take on board comments from each other. They coordinate investigations, where necessary. They are able to exchange evidence and other information and to 
discuss issues of common interest. These arrangements provide a means to ensure the effective and consistent application of competition law across EC national competition authorities.

This position will change for the CMA post-Brexit, at least once any transition period is at an end. Unless membership is specifically negotiated, the UK will not remain part of the ECN. Moreover, the need for close coordination and competition among competition authorities in the EU is limited by the EUMR's exclusive 'one-stop-shop' nature and by the ability of the EC to take control of antitrust proceedings that have effects across a number of Member States. Again, this will change post-Brexit as far as the UK is concerned.

Wherever this loss of centralised enforcement leads to parallel action, whether for merger assessment or antitrust enforcement, this duplication will create significant risks for effective and efficient case delivery, as well as creating higher costs and legal uncertainty for business.

These risks can be ameliorated, if not entirely eliminated, through close coordination and cooperation post-Brexit between the competition authorities involved. This relates not only to the CMA and EC, but also to the CMA and Member State national competition authorities.

We therefore strongly recommend that consideration be given by the UK Government to negotiating the continued participation of the UK within the ECN post-Brexit, or at least the forum for European Competition Authorities (ECA), which includes the EEA authorities. This would be by far the best way of ensuring continued effective and efficient case delivery across parallel investigations.

Absent this, a series of bilateral arrangements will be required. While many bilateral cooperation arrangements currently exist between jurisdictions, it should be noted that they do not typically provide for the same level of cooperation and coordination as exists currently across the ECN. For the most part, these bilateral arrangements effectively codify and record formally what can be expected in terms of good practice by the signatory authorities. For merger control, the EU-US 'Best Practices on Cooperation in Merger Cases' provides the most comprehensive example. It is predicated on the common-sense idea that coordination between authorities avoids conflicting or diverging outcomes, which is best for the parties and for third parties. This applies equally to UK-EU cooperation post-Brexit.

By contrast, very few bilateral cooperation agreements provide for the exchange of confidential information and documents obtained during the course of investigations, as is currently possible within the ECN. Of the EU's existing bilateral cooperation agreements, only one (the 2014 EUSwitzerland agreement) allows for such information-sharing. In this context, it should be noted that while EA02 provides the CMA with a gateway to share specified information with other authorities, this gateway specifically excludes information which has been provided to the authority by parties for merger assessment purposes (section 243(3)(d)).

In the case of mergers, unlike the situation for antitrust, it is likely that merging parties will willingly agree to confidentiality waivers to facilitate cross-jurisdiction coordination. This means that the lack of formal information gateways between the UK and other jurisdictions may be of more limited concern. An agreement along the lines of the EU-US Best Practices one described above will be sufficient in many cases to ensure effective and efficient parallel merger assessment, including around the design and implementation of remedies where required.

This gives rise to the possibility that, if the CMA cannot retain membership of the ECN, the UK government could potentially leave it up to the CMA to set up cooperation agreements with its overseas counterparts in the area of merger assessment. It would be ideal to agree formal information-sharing gateways for mergers, but in many cases they would not in fact be required. We would recommend that priority be given to bilateral agreements with those jurisdictions that have an active merger regime which is likely to be triggered by international deals that could also have a UK nexus. The EU and other major Member State authorities are likely to be most important in this regard.

We also note that, on leaving the EU, the UK will also no longer benefit from the EC's bilateral cooperation arrangements with the US, Canada, Japan, South Korea and Switzerland. The CMA 
may wish to seek similar bilateral arrangements with at least some of these countries as soon as is feasible.

In the case of antitrust, the situation is more complex, as parties are unlikely to give confidentiality waivers willingly, and the ECN information gateways will no longer apply to the UK post-Brexit. Neither the CMA nor the UK Government can unilaterally secure reciprocal information-sharing across jurisdictions. Even if the UK were to keep open its own gateways for the sharing of confidential information, for example by retaining a domestic equivalent of the relevant parts of Regulation 1/2003 through the Repeal Act process, there is no mechanism to oblige those other authorities to share information with the CMA, nor any gateway to allow this legally.

Absent the UK's continued membership of the ECN, a formal cooperation mechanism, and reciprocal information gateways, will therefore need to be put in place between the EU and UK, if parallel antitrust investigations are to continue to run smoothly post-Brexit. Ideally, this agreement would also cover interactions between the CMA and Member State national competition authorities in the same way as between the CMA and EC.

A potential difficulty to be addressed may arise from the fact that UK law has criminal sanctions against cartels. Jurisdictions with civil competition powers only have not wanted to provide confidential information to the US to prevent it being used in criminal proceedings there. However, we note that the EU-Swiss agreement does provide for information-sharing, but restricts Switzerland from using any such information 'to impose sanctions on natural persons'.

Across both mergers and antitrust, it would highly desirable post-Brexit for the UK-EU bilateral agreement to include the following aspects:

- $\quad$ Communication between the authorities at the outset of any investigation for which substantial cooperation might be beneficial and then at various stages through the investigation. (This goes further than the EU-Swiss agreement, for example, which provides for the EC to notify the Swiss of merger investigations only when they reach Phase II.)

- $\quad$ Coordination of investigative timings to the extent possible, including key decision-making stages. (As with the UK/EU processes, the formal mergers timetables of the EU and US processes are different, so the best practices envisage discussions with the merging parties about pre-notification investigative steps and timing of filings.)

- Discussion and coordination of information gathering, where possible relying on the provision of confidentiality waivers by the parties.

- Coordination of remedies to ensure that inconsistent or conflicting remedies are not imposed, to minimize difficulties in implementation, and to achieve a compatible outcome where the authorities may be considering different remedies for similar concerns.

In the antitrust enforcement context, particular issues arise with respect to 'dawn raid' inspections in cartel cases. Currently sections $61-65 \mathrm{~N}$ CA98 create an obligation on the CMA to assist in EC inspections. These sections will presumably no longer apply post-Brexit. However, given the crossborder nature of many major cartels, the effective enforcement of the competition rules would be promoted if the two authorities continued to be able to support each other on a reciprocal basis. This may also be true where there is a cross-border element of a domestic case. There may be cases, for example, in which the CMA needs a dawn raid carried out on a company based inside the EU (or vice versa).

Ideally, any new arrangement would build, as far as possible, on the existing one in place under Regulation $1 / 2003$ and sections $61-65 \mathrm{~N} \mathrm{CA98.} \mathrm{If} \mathrm{this} \mathrm{is} \mathrm{not} \mathrm{feasible} \mathrm{post-Brexit,} \mathrm{arrangements}$ mirroring the cooperation with the US Department of Justice should be considered.

Given that actions based on breaches of Articles 101 and 102 could continue to be brought in the domestic courts, it would be helpful if national courts could continue to communicate with the EC. 
While UK courts may no longer need to avoid inconsistent decisions with those of the EC when determining cases under CA98, there may nevertheless be circumstances in which UK courts may want to request information about the progress of ongoing parallel proceedings or about previous decisions or judgments, for domestic purposes.

Finally, while formal cooperation arrangements are typically useful for case work, less formal measures are also valuable to ensure effective cooperation on wider policy issues. This promotes global enforcement, and also a more consistent policy framework for firms that are active on a global basis. We recommend that the CMA continues to play a strong participatory role in international bodies such as the ICN and OECD.

\section{CMA: RESOURCING, PROCESSES AND PRIORITIES}

\section{A. Antitrust}

As noted above, in a number of cases, the CMA will need to investigate the UK-specific elements of cross-border agreements and conduct that will not be covered by EC enforcement action post-Brexit. However, it may take some time for the increase in cases to take effect (given the retrospective nature of antitrust enforcement and the fact that it can be a number of years before conduct comes to the attention of the authorities).

Nonetheless, given that these matters are likely both to be large in scale, and in some cases far more complex than the vast majority of UK investigations undertaken since CA98 came into effect, we would recommend that the CMA begin to review its procedure and staffing as soon as possible to determine whether it has the appropriate capacity and capabilities for the task ahead. Until this work is done, we would not favour radical changes to the UK regime. Whether or not radical changes warrant contemplation in due course, we advise that a 'wait and see' approach be adopted for now.

We recommend that the Government consider increasing the CMA's budget if a review shows that it currently does not have sufficient resources to deal with this additional workload. This could well be at no cost to the Treasury because expanded antitrust enforcement by the CMA is likely to result in some substantial fines: as a rough indication, EU fines for antitrust infringements currently run at approximately Euro 2 billion per year. The UK's notional 'share' of these fines - assuming that CMA fines would be at a similar level but related to UK turnover - is approximately Euro 300 million. In comparison, the current annual budget of the CMA (across all areas of its activity) is approximately Euro 80 million. From a public finance perspective, additional resources for the CMA to detect and prosecute competition law infringements are likely to be at the very least cost-neutral.

\section{B. Mergers}

The impact of Brexit on resources required for merger review will be more immediate and unavoidable, given that the EC will lose jurisdiction over UK aspects of mergers at Brexit and that merger review is largely non-discretionary. Not all of the additional deals that will fall within the UK jurisdiction will be notified, but a good number will. As many of these mergers will also meet the EUMR thresholds, they will, by definition, be large mergers, involving at least two merger authorities and potentially many more. While some will have limited implications in the UK, or be relatively straightforward to review, many will be complex and will require resource-intensive assessment. Because of the current sectoral focus of EUMR cases, many will cover sectors in which the CMA has little experience. The CMA's case mix is therefore likely to change substantially.

The CMA has estimated that 30-50 additional cases a year will fall within its jurisdiction, with around six of these potentially being Phase II cases in need of in-depth scrutiny. Our own review of the data suggests that these estimates, in particular the number of additional Phase II investigations, are conservative. 
There may be also be an additional resource implication to the extent the CMA has to take on the monitoring of remedies with effect in the UK implemented by the EC in previous merger decisions. However, the use of monitoring trustees in such cases may limit the impact of any such resource demands.

While the CMA may be able to limit the extent of its merger assessment in some cases, and thus ameliorate some of the impact on resource needs arising from the additional mergers falling under its jurisdiction post-Brexit, we nevertheless recommend that the CMA begin to review its procedure and staffing as soon as possible. We believe that the CMA will need to recruit a significant number of additional lawyers and economists skilled and experienced in merger assessment. Without this, and given the largely non-discretionary nature of mergers work, other key areas of the CMA's work, such as antitrust market studies and consumer enforcement, are bound to suffer.

While extra merger resources will require additional funding, this need not be negative for public finances in view of the increase in total merger filing fees associated with the increased number of large mergers under review. Financing competition authority budgets through merger filing fees is common internationally. However, merger filing fees do not currently cover the cost of the UK merger review regime, and thus there may be a need to revisit these fee levels.

In terms of ameliorating the increase in the CMA's mergers workload post-Brexit, a number of alterations to the merger regime have been mooted. However, most of these options would have unattractive consequences.

For example, we would not recommend the introduction of rules limiting the CMA's jurisdiction to mergers above a certain financial threshold, thus avoiding expending resources on smaller cases. Nor would we recommend a significant increase in the existing de minimis thresholds. Both of these options could lead to anticompetitive mergers being excluded from review simply because of their size, which would weaken UK merger regime contrary to the economic and consumer welfare objectives of policy.

Likewise, we would not recommend a requirement that the CMA only investigate mergers that involve a market share in a UK market above a certain threshold (for example, a 20\% threshold). Given the complexities that can arise in defining markets and calculating market share, this could result in the CMA unnecessarily trammelling its ability to investigate mergers that could lead to potentially negative effects on competition in the UK.

Nor do we recommend amending the 'duty to refer' under EA02 to a 'discretion' to refer, or including an exception to the duty to refer where a merger is under review by other authorities in particular the EU. The duty for the CMA to carry out an in-depth investigation into mergers that raise significant concerns is a key element of the merger regime. Softening this duty would run the risk that anticompetitive mergers are approved (and without scope for third parties to challenge approval) simply because the authority is unable or unwilling (perhaps under political pressure) to carry out a full investigation.

More positively, we note that there may be cases where it may be possible for the CMA to work closely with other merger authorities, including the EC, and to focus on cases where the effects on the UK market, or required remedies, are likely to be significantly different from those in these other jurisdictions. This would, for example, avoid the CMA expending excessive resources on cases that are likely to be prohibited by the EC in any event. The current SLC test is adequate to allow for this by considering, as the 'counterfactual' against which a merger is assessed, a situation which includes remedies imposed in other jurisdictions.

This option will still, however, require the CMA to carry out sufficient investigation to determine whether remedies imposed in other jurisdictions will be sufficient to address UK concerns. Where this is not the case, a full UK assessment would still be needed. The resource savings from this approach may ultimately therefore be relatively small. 
Other options open to the CMA involve shortening or simplifying the current review processes (whether by legislative changes to EA02 timescales or by administrative practice). In our view, these are all worth considering:

- A shortened, simplified Phase II procedure could be introduced for parallel EC/UK cases, which would allow the CMA to take into account and rely on the findings and remedies of the EC and thus close cases without completing its own in-depth review. This option would require close cooperation between the CMA and the $\mathrm{EC}$ in order for the CMA to have the necessary confidence to rely on the EC's findings and remedies with respect to the concerns that it has identified in the UK.

- $\quad$ As a matter of its own practice, the CMA could produce shorter Phase I decisions for cases that do not raise issues and/or streamline the process to reduce the market investigation steps taken in non-problematic cases.

- $\quad$ The CMA could target information requests and focus the Phase I analysis on a narrower range of issues (for example, only where overlaps are above a certain threshold or competitor presence is limited).

- $\quad$ The CMA could create a simplified Phase I procedure, with smaller informational burdens and more limited investigative steps, for non-problematic deals.

An institutional change that we strongly recommend against would be for the exclusive competence of the CMA in UK merger control to be diluted. While input from sector regulators can be valuable, the disadvantages of sectoral regulators undertaking merger control functions would significantly outweigh the advantages. The CMA's exclusive competence in this area ensures consistency of practice and coherent application of the merger regime, and also allows for a single UK point of contact with mergers authorities in other jurisdictions. It also ensures that decisions are made purely on competition grounds. There is also a far lower risk of regulatory capture or mission creep than with review by sector regulators.

While resourcing is perhaps the key immediate challenge for the merger regime, it has been put to us that the removal of the EU jurisdiction over large transactions affecting the UK might require the adoption of a compulsory, suspensory merger notification system similar to that under the EUMR to ensure the CMA is able to review such cases deals in good time.

We recommend against a move to a mandatory regime for a number of reasons.

- $\quad$ First, it seems inconceivable to us that a large, potentially problematic deal, which is likely to be subject to merger review in other jurisdictions including the EU, would either not be notified to the CMA by the parties or somehow fall below the radar of its Mergers Intelligence Unit.

- $\quad$ Second, the resource implications of such a system would be considerable. The EUMR currently catches a very large number of deals (over $80 \%$ of its caseload) which raise no competition issues. Adopting a system that would recreate this in the UK would not seem the best use of resources, particularly given the additional demands that Brexit entails for the CMA. Moreover, the CMA is geared to conduct a thorough review of potentially problematic deals, and it would take a large cultural shift for it to become an efficient processor of non-issue transactions on the one hand, and retain its thorough approach to others.

- $\quad$ Third, subjecting such a large number of no-issue cases to mandatory UK review would impose costs on business for no obvious public policy benefit.

- $\quad$ Fourth, the adoption of a 'standard' mandatory model would require design of jurisdictional thresholds at a time when resources dedicated to reform are likely to be stretched. The Government would need to determine the appropriate turnover level. It would also need to consider whether to allow review of deals below the mandatory notification thresholds or to accept smaller mergers, even to monopoly, that fall outside the regime. Previous reform 
debates highlight that the policy challenges of dealing with these two issues should not be under-estimated.

A hybrid/partial model might side-step some of these issues by requiring notification only of larger mergers (e.g., those that would have been subject to notification under the EUMR). That would preserve the CMA's ability to 'call-in' any deal, thereby allowing it to address smaller anticompetitive mergers, much as is does now. However, it would still result in a large number of unproblematic cases being caught. So we would not favour its adoption at this point but would suggest that the CMA keep the matter under review in the light of experience in the first few years after Brexit.

In the longer run, the CMA may wish to consider revisiting its merger timetables to align more closely with the EC's timetables. Having a more coordinated timetable for merger clearance may enhance the efficiency and legal certainty of the cross-European merger regime (including EU and UK). That said, we recognise that the EC's process involves considerably longer pre-notification contacts than the UK and that amending timetables would be a costly effort. We also note that the CMA has flexibility, within the current framework, to adjust its timetables in order to coordinate its assessment with other authorities, and indeed that it frequently does so. We would therefore recommend that the CMA gain post-Brexit experience of parallel merger reviews before it considers whether and how best to revisit its own timetables to this end.

\section{Priorities}

The resources available to the CMA are one thing; the uses to which those resources are put is another. The CMA will need to take particular care in managing its resources that the pressures of increased merger work do not unduly squeeze its other work - on market studies and investigations, on competition advocacy, on consumer law enforcement, and on antitrust enforcement itself.

\section{THE EFTA OPTION}

The working assumption of this Report has been that upon Brexit the UK will leave the EEA as well as the EU. There is however a possibility that, perhaps for a transitional period, the UK would become a member of EFTA' and thereby remain a member of the EEA for the time being. (This 'EFTA option' is sometimes referred to as 'the Norway option'.) In this Section we consider what it would mean for UK competition law and policy.

Compared to EU Member States, EFTA States in the EEA maintain their sovereignty over several areas of policy, including agriculture, fisheries, external trade, regional and foreign policy. There is also no commitment within the EEA Agreement to the goal of 'ever closer union'. EEA countries outside the EU are, however, in principle still required to comply with transposed EU laws 28 in the following areas: the single market, social policy, environmental policy, state aid, transport, financial services, consumer protection, company law and - of particular relevance for our purposes competition policy.

If the UK remained within the EEA, what would be the implications for UK competition law? In short, far fewer changes would be required than if the UK left the EU without joining EFTA.

That is because most EU law and practice relating to competition policy is replicated within the wider EEA. The EEA Agreement contains equivalent provisions to Articles 101 and 102 (i.e., Articles 53 and 54 EEA) and also equivalent merger rules. The procedural rules relevant to the application of the

28 It is frequently said that a drawback of being an EFTA State is that they have to comply with EU laws without having influence over their content, and it is true that those countries do not have votes in the European Council or European Parliament, or any European Commission staff or Commissioners. EFTA countries are, however, consulted on any proposals for new EU laws, and civil servants and technical experts from EFTA countries participate in putting together draft proposals in the same way as experts from EU Member States. 
EEA competition rules by the EFTA Surveillance Authority are set out in Part II of, and Protocol 4 to, the Surveillance and Court Agreement, and they are very similar to the procedural rules in EC Regulation $1 / 2003$. The key pieces of implementing and subsidiary legislation, such as the vertical restraints block exemption, and Commission guidelines such as those on market definition, apply across the whole of the EEA as well as within the EU. Typically, the EFTA States will either provide that the EU provision should apply within their areas with appropriate consequential amendments, or the EFTA institutions publish their own provision that is largely identical in substance.

The EFTA Surveillance Authority has equivalent powers and similar functions to those of the Commission for the purpose of applying the competition rules. Cooperation arrangements are already in place governing the allocation of jurisdiction between the two bodies in competition investigations and merger cases, although in practice the Commission takes the lead on mergers. Arrangements are also in place for information sharing between the two supra-national authorities, and for coordination between the EFTA Surveillance Authority and the national competition authorities of the EFTA States, which participate in the European Competition Network alongside EU Member States.

In the judicial field, the EFTA Court hears appeals in competition cases in the same way as the General Court and the Court of Justice within the EU, although it is only a single instance court rather than a two-tier appeal structure. The EFTA Court is staffed by judges from the EFTA States and sits in Luxembourg, just across the street from the Court of Justice. Its working language is English.

In terms of the changes that would be required within the UK legal system, the UK is already a contracting party to the EEA, and the European Communities Act 1972 applies to the provisions of the EEA Agreement as well as to the EU Treaties. However, if the UK left the EU and joined EFTA it seems likely that a new piece of implementing legislation would be put in place.

As the wider EEA rules and procedures are broadly equivalent to those within the EU, any amendments to UK legislation would generally be consequential rather than substantive, e.g., references to Article 101, the European Commission and the EU courts would need to be replaced with references to Article 53, the EFTA Surveillance Authority and the EFTA Court. Similar changes would be required to the competition law guidelines published by the CMA and sectoral regulators.

UK membership of EFTA would, however, almost certainly have implications for the operation of EFTA institutions. As well as the influence that a UK judge would have within the EFTA Court, the EFTA Surveillance Authority would also gain a UK college member and would potentially be far better resourced and able to expand the number and scope of its competition investigations. It would also have much more work to do.

\section{SUMMARY AND CONCLUSIONS}

Our view is that the interests of the UK economy, and those of businesses and consumers within it, will be best served by continuity of UK competition law and policy, so far as is possible following Brexit.

Brexit does not give cause for radical reform of the principal UK competition statutes, nor of the role of the competition authorities. Indeed, the challenges that Brexit poses to the effective operation of various areas of competition policy argue against contemplation of radical reform, at least for the time being.

Primary legislation will nevertheless require amendment. In particular, we recommend that the duty in section 60 CA98 for the UK authorities and courts to act consistently with European jurisprudence becomes simply a duty to 'have regard to' that jurisprudence. We also recommend repeal of section 10 CA98 so that future (as distinct from existing) EU block exemptions from the competition rules are not automatically imported into the UK; they would instead become a matter for the UK to decide. Brexit should cause some current exemptions, notably that for agricultural products, to fall away. As 
to the territorial scope of CA98, there is a strong case for revising section 2(3) so that agreements with anti-competitive effects in the UK do not escape prohibition by virtue of being 'implemented' outside the UK. To preserve continuity of the ability of private parties to bring actions for damages in the UK for breaches of EU (as well as UK) competition law, we recommend retaining the provisions of sections 47 and 58 CA98.

For mergers and market investigations we recommend retaining the existing statutory criteria, notably the 'substantial lessening of competition' test for mergers. Likewise, we would not vary the existing public interest criteria. For market investigation references, while the CMA should not have an unfettered discretion in its choice of legal instrument when investigating agreements that might be harmful to competition, we recommend against retaining a domestic analogue of the current EU provision that precludes remedies relating to agreements between firms that go further than the antitrust rules.

Brexit poses formidable issues concerning transitional arrangements, future cooperation between UK and EU authorities, and the resources that the CMA will need to carry out a substantially expanded caseload. In relation to transition issues, we have made a series of recommendations on the carrying forward of commitments from past antitrust and merger cases, and of leniency arrangements. Particularly difficult issues could arise in relation to mergers that 'straddle' the date of Brexit, and (in the longer run) parallel UK/EC investigations, both of mergers and antitrust issues. These do not have easy solutions but we identify ways to ameliorate them, and stress the importance of measures being taken and communicated well ahead of the date of Brexit. These are matters in relation to which the UK and EC authorities should have strong interests in common.

On resources we note that, beyond transitional issues, the CMA is likely to have a substantial number of large and complex merger cases each year that would previously have been reviewed by the EC (including for effects on UK markets). Even with some adjustment of CMA priorities and procedures (transfer of powers to other bodies should be avoided), a substantial increase in resources will be needed if other activities are not to get squeezed. This resource will need to be in place by Brexit, if other important elements of the CMA's work portfolio are not to be squeezed out by urgent and nondiscretionary mergers work. Over time, the CMA is also likely to require additional resources for its antitrust enforcement work. Bearing in mind merger filing fees and competition fines, this need not involve cost to the public purse.

There are aspects of EU competition law that this report has not addressed - notably state aid, which will no longer apply to the UK after Brexit. As selective industrial subsidies are generally costly to the economy and distort competition inefficiently, the UK should be open to agreeing to adopt an equivalent to the EU state aid regime domestically. 